\title{
PROPOSAL LAYANAN PEMBUATAN WEBSITE DAN PEMASANGAN DOMAIN
}

\section{Voreate}

Nama : Fathur Rizki

Nim : 0702183243

Mata Kuliah : Sistem Informasi Manajemen

Dosen Pengampu : Dr.Yahfizam, S.T., M.Cs

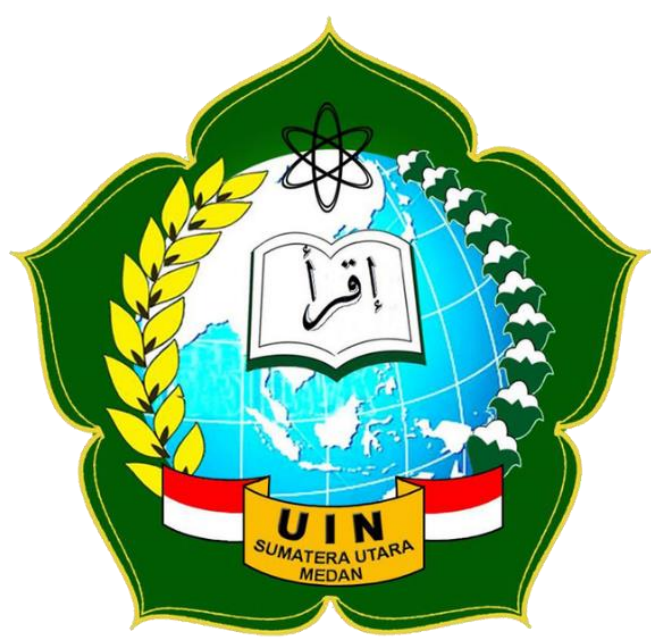

FAKULTAS SAINS DAN TEKNOLOGI

UNIVERSITAS ISLAM NEGERI SUMATERA UTARA 


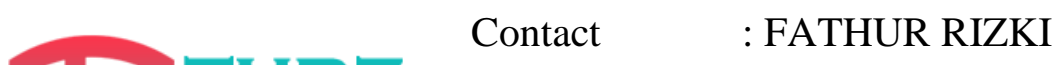 \\ Whatsapp / HP : 081262334036 \\ Email : fathurrizki27@gmail.com}

$\begin{array}{ll}\text { Lampiran } & : 1(\mathrm{Satu}) \text { set Proposal } \\ \text { Perihal } & : \text { Layanan Pembuatan Website dan Pemasangan Domain }\end{array}$

Kepada Yth.

Bapak/Ibu Pemimpin

Di Tempat

Dengan hormat,

Dengan adanya surat ini, Kami dari Turz Creatif yang bergerak dalam bidang pembuatan website dan pemasangan domain, hendak menawarkan produk kami kepada perusahaan Bapak. Kami menawarkan produk kami yang tentunya berkualitas dan dengan harga murah lengkap dengan garansi selamanya.

Saat ini kami membuka layanan pembuatan website dari google platform yaitu blogspot.com tentunya dengan menggunakan theme (tema) yang responsive baik dilihat dari pc, laptop, headphone, dan tablet. Untuk contoh theme yang tersedia dapat dilihat pada proposal dibawah, dan Domain yang kami sediakan yaitu :

.COM, .ID, .XYZ, .CO.ID, .NET, .ORG, .ONLINE, .SITE dan untuk domain lainnya silahkan contact kami agar dapat kami cek ketersediaan domainnya.

Medan, 27 Juli 2021

Hormat Saya 


\section{LATAR BELAKANG}

Di masa modern seperti sekarang ini semakin canggih sebuah internet, maka semakin banyak pula website yang dapat dijumpai di internet, salah satunya platform pencarian terbesar yaitu Google.com. setiap pencarian yang kita lakukan pada Google, hampir semua yang kita ingin cari atau ingin kita tahu sudah tersedia jawabannya di Google. Terlebih lagi setiap website yang menyajikan jawaban dari apa yang kita cari, dan juga setiap website memiliki Theme atau tampilan, domain, serta hosting yang berbeda - beda. Sebelum ketahap selanjutnya saya akan menyampaikan pengertian dari Website, Website merupakan suatu halaman yang menyampaikan sebuah informasi yang dapat di akses setiap orang melalui internet, cukup dengan mengetik di kolom pencarian maka kalian akan menemukan apa yang ingin dicari. Pada proposal ini saya akan menawarkan sebuah layanan pemasangan domain dan hosting untuk sebuah website, baik dari Blogspot.com atau Wordpress.com sebelumnya saya akan menyampaikan apa pengertian dari Domain dan Theme pada sebuah website.

\section{DOMAIN}

Jika sebuah website dikatakan produk maka domain pada website bisa disebut dengan merk, pada website yang menggunakan domain yang menarik tentunya akan membuat orang akan tertarik untuk memasuki suatu website, terlebih lagi website tersebut sesuai dengan apa yang sedang orang cari dan memiliki tampilan yang menarik. Domain adalah sebuah alamat IP yang menggunakan kombinasi angka rumit, fungsi dari Domain ini yaitu sebagai alat untuk mengidentifikasikan sebuah web hosting. Pada layanan ini domain yang tersedia antara lain yaitu : .COM, .ID, .XYZ, .CO.ID, .NET, .ORG, .ONLINE, .SITE, serta untuk domain lainnya silahkan hubungi contact person ke nomor Whatsapp saya yang tertera dibawah. Fungsi domain yang lainnya yaitu untuk memberikan kesan professional pada tampilan website, dan tentunya memberikan kepercayaan pada orang yang mengunjungi website kita jika memiliki domain yang benar seperti .com, .net ataupun .co.id

\section{THEME}

Theme atau template pada sebuah website merupakan suatu file atau bahan dokumen yang sangat berguna bagi seorang blogger maupun webmaster. Theme pada website adalah tampilan sebuah design dari halaman website yang berisi berbagai tampilan baik dari menu, sidebar,dengan tampilan yang unik dan enak untuk dilihat pengunjung.

Untuk tampilan dari theme yang tersedia pada layanan ini dapat dilihat di demo berikut :

https://voltaspeed.blogspot.com/

https://sweetwinsister.blogspot.com/

https://pixelarlina.blogspot.com/

https://kezeltheme.blogspot.com/

https://lunarblogid.blogspot.com/ 


\section{JENIS PAKET LAYANAN DOMAIN}

Untuk harga layanan domain dibawah ini harga pemasangan awal yang artinya dapat berubah sewaktu-waktu, seperti domain .XYZ dan .SITE

Harga Domain :

\begin{tabular}{|l|l|}
\hline. COM & Rp. 115.000 \\
\hline .ID & Rp. 200.000 \\
\hline .XYZ & Rp. 18.000 \\
\hline .CO.ID & Rp. 275.000 \\
\hline .NET & Rp. 155.000 \\
\hline .ORG & Rp. 175.000 \\
\hline .ONLINE & Rp. 15.000 \\
\hline .SITE & Rp. 14.000 \\
\hline
\end{tabular}

\section{. $\mathrm{COM}$ \\ Ekstensi nama domain paling populer \\ Rp. 145.000 - \\ Rp. 115.000,- \\ Daftar}

\section{.NET}

Buat nama domain unik dan kreatif tanpa batas

Rp. 155.000,-

\section{.ID}

Top Level Domain Indonesia untuk personal dan institusi

Rp. 200.000,-

Daftar

\section{.ORG}

Domain untuk organisasi, komunitas, atau lembaga

Rp. 175.000,-

\section{. $\mathrm{XYZ}$}

Ciptakan citra modern dan unik dengan domain ini

Rp. 140.000

Rp. 18.000,-

\section{Daftar}

\section{.ONLINE}

Cocok untuk kepentingan personal atau profesional

Rp. 15.000,-

\section{.CO.ID}

Ekstensi nama domain untuk perusahaan/institusi di

Indonesia

Rp. 275.000,-

\section{SITE}

Tetap tunjukkan kesan profesional dengan domain ini

Rp. 14.000 ,- 


\section{JENIS PAKET LAYANAN THEME}

Harga Theme dibawah ini sudah termasuk harga update jika kedepannya ada update dari tiap theme karena untuk memaksimalkan kinerja dari tampilan pada website yang lebih baik. untuk

Harga Theme :

\begin{tabular}{|l|l|}
\hline Theme Volta & Rp. 100.000 \\
\hline Theme Mini Site & Rp. 100.000 \\
\hline Theme Pixel & Rp. 150.000 \\
\hline Theme Kezel & Rp. 100.000 \\
\hline Theme Lunar & Rp. 120.000 \\
\hline Theme Vikka Pro & Rp. 130.000 \\
\hline
\end{tabular}

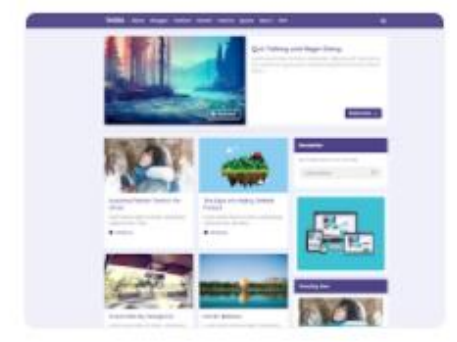

Volta

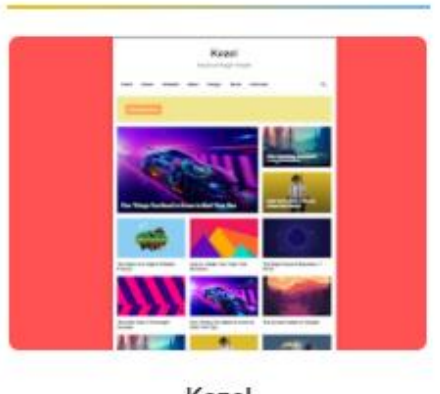

Kezel

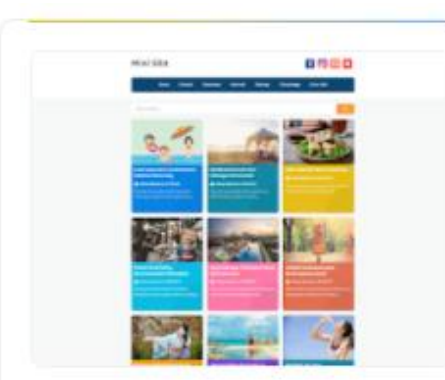

Mini Site

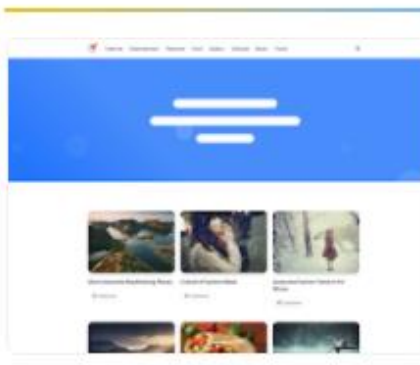

Lunar

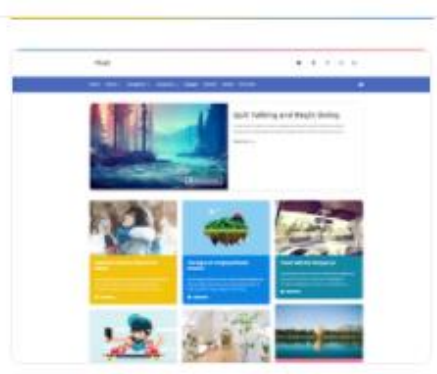

Pixel

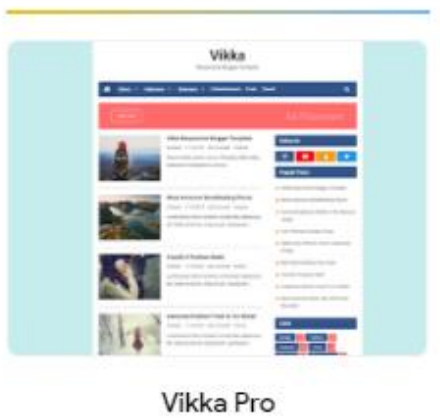

Adapun harga paket pembuatan website dan pemasangan domain yang pastinya lebih murah :

1. Biaya Pemasangan Rp.50.000 - 100.000

2. Untuk domain COM, .ID, .CO.ID, .NET, .ORG + Theme dapat discount $20 \%$

3. Untuk domain .XYZ, .ONLINE, .SITE + Theme tidak dapat discount. 


\section{BEBERAPA ALASAN MENGAPA MEMILIH LAYANAN TURZ CREATE :}

1. Pengerjaan cepat, pesanan masuk langsung dikerjakan dihari yang sama.

2. Theme atau tampilan yang digunakan memiliki feature sebagai berikut :

- Responsive

- Mobile Friendly

- Google pagespeed insights

- Google testing tools

- SEO Friendly

- 2 Column

- 3 Version

- Breadcrums schema.org

- Related post

- Responsive menu navigation

- Share button

- Shortcode

- Blogger and Disqus comment

- Documentation

- Free update theme

3. Konsultasi 24 jam / 7 days

4. Cepat respon jika ada problem dengan website yang dibuat.

5. Dan tentunya harga murah dan berkualitas.

\section{PENUTUP}

Demikian proposal penawaran layanan ini kami perbuat. Atas perhatian dan kerjasamanya, kami ucapkan terima kasih. Dan semoga kita dapat menjalin hubungan kerjasama yang lebih baik disaat ini dan masa depan. 